\title{
BMJ Open Relationship of different domains of physical activity practice with health- related quality of life among community-dwelling older people: a cross-sectional study
}

Catarina Covolo Scarabottolo, ${ }^{1}$ Edilson Serpeloni Cyrino, ${ }^{2}$
Priscila Missaki Nakamura, ${ }^{3}$ William Rodrigues Tebar, ${ }^{1}$ Daniel da Silva Canhin, ${ }^{1}$
Luis Alberto Gobbo, ${ }^{1}$ Diego Giulliano Destro Christofaro ${ }^{1}$

To cite: Scarabottolo CC, Cyrino ES, Nakamura PM, et al. Relationship of different domains of physical activity practice with health-related quality of life among community-dwelling older people: a crosssectional study. BMJ Open 2019;9:e027751. doi:10.1136/ bmjopen-2018-027751

- Prepublication history for this paper is available online. To view these files, please visit the journal online (http://dx.doi. org/10.1136/bmjopen-2018027751).

Received 6 November 2018 Revised 20 March 2019 Accepted 2 May 2019

Check for updates

(c) Author(s) (or their employer(s)) 2019. Re-use permitted under CC BY-NC. No commercial re-use. See rights and permissions. Published by BMJ.

For numbered affiliations see end of article.

Correspondence to Dr Diego Giulliano Destro Christofaro; diego.christofaro@unesp.br

\section{ABSTRACT}

Objective To analyse the association between different domains of physical activity (PA) and health-related domains of health-related quality of life (HRQoL) in older adults, independent of confounding variables.

Design Cross-sectional study.

Participants In total, 400 individuals 60 years or above were randomly selected to participate in the study.

Primary and secondary outcome measures PA was assessed by a questionnaire in three different domains (work/occupational, sports/gym and leisure time) and total PA. The 36-Item Short Form Health Survey was used to evaluate HRQoL. The variables socioeconomic condition, marital status and presence of health professionaldiagnosed comorbidities were self-reported.

Results The mean age of the sample was $71.5( \pm 8.4)$ years, of whom $58 \%(n=232)$ were female. Male older adults showed higher scores of PA in sports, leisure time and in total PA than female adults. Older adults who were more physically active in the work/occupational domain were associated with better scores in functional capacity $(\mathrm{OR}=1.73,95 \% \mathrm{Cl} 1.02$ to 2.93$)$ and general health perception $(\mathrm{OR}=1.61,95 \% \mathrm{Cl} 1.02$ to 2.56$)$. Those who presented a higher score in the sports/gym domain had better scores in functional capacity, even after adjustment for comorbidities $(\mathrm{OR}=1.72,95 \% \mathrm{Cl} 1.01$ to 2.96). Individuals with higher activity in leisure time were more likely to have better scores in functional capacity $(\mathrm{OR}=1.75,95 \% \mathrm{Cl} 1.03$ to 2.98$)$, body pain $(\mathrm{OR}=1.74,95 \%$ $\mathrm{Cl} 1.09$ to 2.78) and mental health $(\mathrm{OR}=1.67,95 \% \mathrm{Cl} 1.03$ to 2.69). Older adults who were more active in total PA were $77 \%$ more likely to have better scores in functional capacity (OR=1.77, 95\% Cl 1.04 to 3.02).

Conclusion Physically active older adults in the different domains of PA presented better HRQoL parameters, reinforcing the importance of studies analysing PA in different contexts and in countries with low and medium socioeconomic conditions.

\section{INTRODUCTION}

Insufficient physical activity (PA) is among the top 10 health risk factors ${ }^{1}$ and is the
Strengths and limitations of this study

- This study has a cross-sectional design that does not allow cause-and-effect inference.

- The use of a questionnaire to assess the level of physical activity did not allow a more robust assessment.

- We highlight the random sample, as well as the sample size of older adults, and the control of the variables by confounding factors in the analyses between physical activity and health-related quality of life.

- The evaluation of physical activity addressing different domains in older adults and considering the different domains of health-related quality of life is a

- It is worth noting the collection and storage of data through electronic devices to minimise errors during data export and tabulation, which are complex tasks in a population study.

fourth cause of mortality in the world. ${ }^{2}$ In 2015, non-communicable chronic diseases accounted for $70 \%$ of deaths globally, with $78 \%$ of these deaths occurring in countries with low and medium socioeconomic status. ${ }^{3}$

The benefits that regular PA can provide are well established, and yet the global pandemic of insufficient PA remains. ${ }^{4}$ Benefits promoted by PA can be explored through different domains: (1) work/occupation, comprising PAs performed in the work environment or in domestic activities or gardening; (2) leisure time, corresponding to activities in the off-work time and in regard to active commuting by cycling or walking; and (3) sports practices/gym, comprising PAs performed in sports modalities or physical training. In this sense, there are some strength of the study. 
factors that can influence the prevalence of physically active people in each of the domains, such as cultural and demographic issues, as well as sex and chronological age. $^{56}$

Both physical health and mental health influence quality of life, which is understood as a subjective and multifactorial parameter. ${ }^{7}$ Health-related quality of life (HRQoL) includes different domains in relation to how individuals feel about their experiences, involving perceptions of physical and psychological health, functional and social aspects, and general condition of life, making it an important part of any clinical examination. ${ }^{89}$ Some studies affirm that physically active individuals are more likely to present better quality of life ${ }^{1011}$ and/or better HRQoL parameters. ${ }^{12-15}$ However, little is known about this relation when these two variables (PA and HRQoL) are analysed, separated by different domains. Studies carried out in Brazil with older adults considering this issue used the total PA measure. ${ }^{1011}$

Currently, the older adult population is the fastest growing segment in the world..$^{16}$ In Brazil, the estimation is that the older adult population, composed of 14 million people in 2010, will be around 70.5 million people by $2060,{ }^{17}$ and it is known that the more chronological age increases, the less physically active people become. ${ }^{18}$ Thus, the physiological and cognitive declines that occur naturally during the ageing process can be aggravated when individuals adopt lifestyle habits with insufficient PA, ${ }^{19}$ affecting general health and HRQoL.

Evaluation and continuous monitoring of PA by domains can help in the execution of interventions to promote PA more effectively. It is unclear in the literature whether the PA level of older adults, separated into each of the PA domains, is associated differently with HRQoL, or if this relationship is independent of confounding variables such as gender, age and socioeconomic status, since these variables may be related to quality of life ${ }^{2021}$ and PA. ${ }^{22}$

Thus, the objective of the present study was to analyse the different domains of PA practice and possible associations with HRQoL in older adults.

\section{METHODS}

\section{Sample calculation}

This is a cross-sectional study composed of older adults of the city of Presidente Prudente, Brazil. Presidente Prudente is located in the western region of the state of São Paulo, Brazil, with a Human Development Index (indicator of human development level, ranging from 0 (poor) to 1 (better)) of 0.806 and approximately 207610 people. ${ }^{23}$ Considering that the prevalence of HRQoL in different domains is not consensual in the literature and a previous pilot study was not carried out, a prevalence of $50 \%$ for unknown binary outcome was used, which is considered as a conservative solution and maximises the sample size for a common outcome in epidemiological descriptive studies. ${ }^{24}$ Thus, a tolerable error of $5 \%$ and a study power of $80 \%$ were also considered, resulting in a minimum sample size of 379 . At the end of the study, a total of 419 older adults were evaluated, with exclusion of 19 participants for incomplete PA or HRQoL data, resulting in 400 older adults for data analysis.

\section{Participant selection process}

The city of Presidente Prudente does not have a clear geographical or demographical division. In this sense, with the support of the city map, postal codes and the list of streets available on the city council website, the city of Presidente Prudente was divided into five geographical regions (north, south, east, west and central). In each of these regions, a list of all districts and streets were compiled, which were randomly selected for being visited. In this way, all streets in each region had the opportunity to be selected. The researchers were distributed in pairs to perform recruitment of the participants, door to door, and all the residences of the selected streets were approached once. After explaining the research, all individuals from each household who met the inclusion criteria were invited to participate in the study. Participants were instructed to make a chair available and the research was conducted in front of the home or inside the house. In cases where the participant declined to participate, the next household was visited, until the required sample size had been reached.

The following inclusion criteria were considered: (1) age equal to or greater than 60 years and (2) resident in the city of Presidente Prudente for at least 2 years. The exclusion criteria were (1) being in a wheelchair or other disabilities that do not allow the individual to stand and walk and consequently present an underestimation of habitual practice of PA measured by the adopted questionnaire; and (2) presenting any kind of cognitive deficiency that would prevent understanding of the questions. All participants signed the patient consent form. The group of interviewers was composed of graduate and postgraduate students, all of whom received previous training. The interviews lasted approximately $40 \mathrm{~min}$, and the survey was conducted between March 2016 and February 2017.

\section{Comorbidities}

The participants were asked if they had the following chronic diseases diagnosed by a health professional: hypertension, diabetes, elevated low-density lipoprotein (LDL) cholesterol and elevated triglycerides. They were required to answer 'Yes' or 'No' for each comorbidity. This information was used to adjustment of the analysis.

\section{Anthropometry}

Anthropometric measurements were performed to measure body mass and height, using a digital scale, Wiso brand (model: w912, lot: 13A01, China), and a portable stadiometer with a maximum length of $2 \mathrm{~m}$, respectively. All measurements were performed according to the description of Freitas et al. ${ }^{25}$ Thus, body mass index was 
calculated using the following equation: body mass (in $\mathrm{kg}$ ) divided by height (in $\mathrm{m}^{2}$ ).

\section{PA practice}

PA practice was measured using the Baecke Questionnaire, ${ }^{26}$ previously validated for Brazilian older adults. ${ }^{27}$ This questionnaire evaluates the total PA in three domains: PA in the work environment or in domestic occupations (8 items), PA in sports practices or in activities performed at a gym (10 items), and PA during leisure time or during transportation (4 items). The questionnaire contains a Likert scale with the following answer options: never, rarely, sometimes, often and always. At the end, the instrument provides a dimensionless score in relation to the practice of PA in each of the three domains, as well as a total score from the sum of these three domains. The older adults in the highest quartile (Q4) were classified as 'highly active' and those in the lower quartiles were classified as 'less active' (Q1, Q2 and Q3).

\section{Health-related quality of life}

HRQoL was evaluated using the 36-Item Short Form Health Survey (SF-36). The SF-36 questionnaire consists of 36 items covering 8 domains: functional capacity, physical limitations, body pain, general health perception, vitality, social aspects, emotional limitations and mental health. The SF-36 questionnaire presents a final score of $0-100$, where 0 represents the worst score and 100 represents the best score in relation to the general state of health and quality of life. ${ }^{28}$ The sample was divided into quartiles, with those located in the highest quartile (Q4) classified as having high HRQoL and those in the lower quartiles classified as having low HRQoL (Q1, Q2 and Q3).

\section{Sociodemographic variables}

The 'Brazilian Economic Classification Criteria' was used to determine the economic condition of the families, established in 2014 by the Brazilian Association of Research Companies, according to a survey database carried out in 2009 by the Brazilian Institute of Public Opinion and Statistics. ${ }^{29}$ The questionnaire takes into account the degree of education and the presence and quantity of certain rooms and belongings in the analysed home (bathrooms, domestic servants, automobiles, microcomputer/computers, dishwasher, refrigerator, freezer, DVD player, washing machine and dryer machine). It establishes the following classifications for economic condition: A1, B1, B2, C1, C2 and D-E. After classification of the participants using the questionnaire, the sample was distributed into high economic class composed of categories A1 and B1, average economic class composed of classes B2 and C1, and low economic class composed of categories C2 and D-E. Marital status was self-reported using the following options: (1) single, (2) married, (3) widower and (4) divorced.

\section{Data collection and storage}

All data were collected electronically using tablets (Galaxy Tab 3 WFI 7PBCO2, Galaxy Tab 3 T2100, Tablet DL TP258PIN) or cellular phones with an android system (Motorola XT1032, Samsung Galaxy SM-G530H) through the Open Data Kit program. This tool stores all the information without needing an internet connection. Subsequently, data are sent to a storage platform using an internet connection and exported to an Excel spreadsheet for data analysis.

\section{Statistical analysis}

The sample characteristics are presented as median and IQR, compared between sex by the Mann-Whitney $\mathrm{U}$ test for non-parametric data. Data on the practice of PA and HRQoL in the population of the present study were presented in frequencies. The associations of PA practice in the different domains and in its totality with HRQoL were analysed through the $\mathrm{X}^{2}$ test. The magnitude of these associations was verified through binary logistic regression in two models. Model 1 was adjusted by sex, age, marital status and socioeconomic condition, and model 2 by the variables of model 1 plus the presence of the reported comorbidities (hypertension, diabetes, elevated LDL cholesterol and elevated triglycerides) simultaneously. The statistical program used was SPSS V.20.0, with a CI of $95 \%$ and level of significance set as $\mathrm{p}<0.05$. Aiming to reduce the probability of type I errors due to the multiple comparison tests performed in the regression models, an extra analysis with a CI of $99 \%$ was adopted to provide more robust adjustment of evidence.

\section{Patient and public involvement}

Patients and or the public were not involved in the research.

\section{RESULTS}

In total, 400 older adults, with a mean age of $71.5( \pm 8.4)$ years, participated in the study, of whom 232 were female $(58 \%)$. With regard to marital status, the majority of the sample was married (55.8\%), followed by widower $(23.4 \%)$, divorced $(10.3 \%)$ and single $(9.3 \%)$, while $1.2 \%$ did not respond. The reported comorbidities were observed in $63.9 \%$ for hypertension, $24.1 \%$ for diabetes, $24.9 \%$ for elevated LDL cholesterol and $11.1 \%$ for elevated triglycerides. In relation to the PA level, the proportion of highly physically active individuals was higher among men than women in total score $(39.3 \%$ (95\% CI 34.5 to 44.0 ) vs $17.8 \%$ (95\% CI 14.0 to 21.5 )), in leisure time ( $47.5 \%$ (95\% CI 42.6 to 52.4 ) vs $17.8 \%$ (95\% CI 14.0 to $21.5)$ ) and in the sports domain $(38.0 \%$ (95\% CI 33.2 to 42.8 ) vs $22.5 \%$ (95\% CI 18.4 to 26.6 )), and lower among men than women only in the work/occupational domain (23.5\% (95\% CI 19.3 to 27.7 ) vs $36.8 \%$ (95\% CI 32.0 to $41.5)$ ). Table 1 shows the characteristics of the sample and comparisons according to sex. 
Table 1 Characterisation of the sample ( $N=400$, Presidente Prudente, São Paulo, Brazil, 2017)

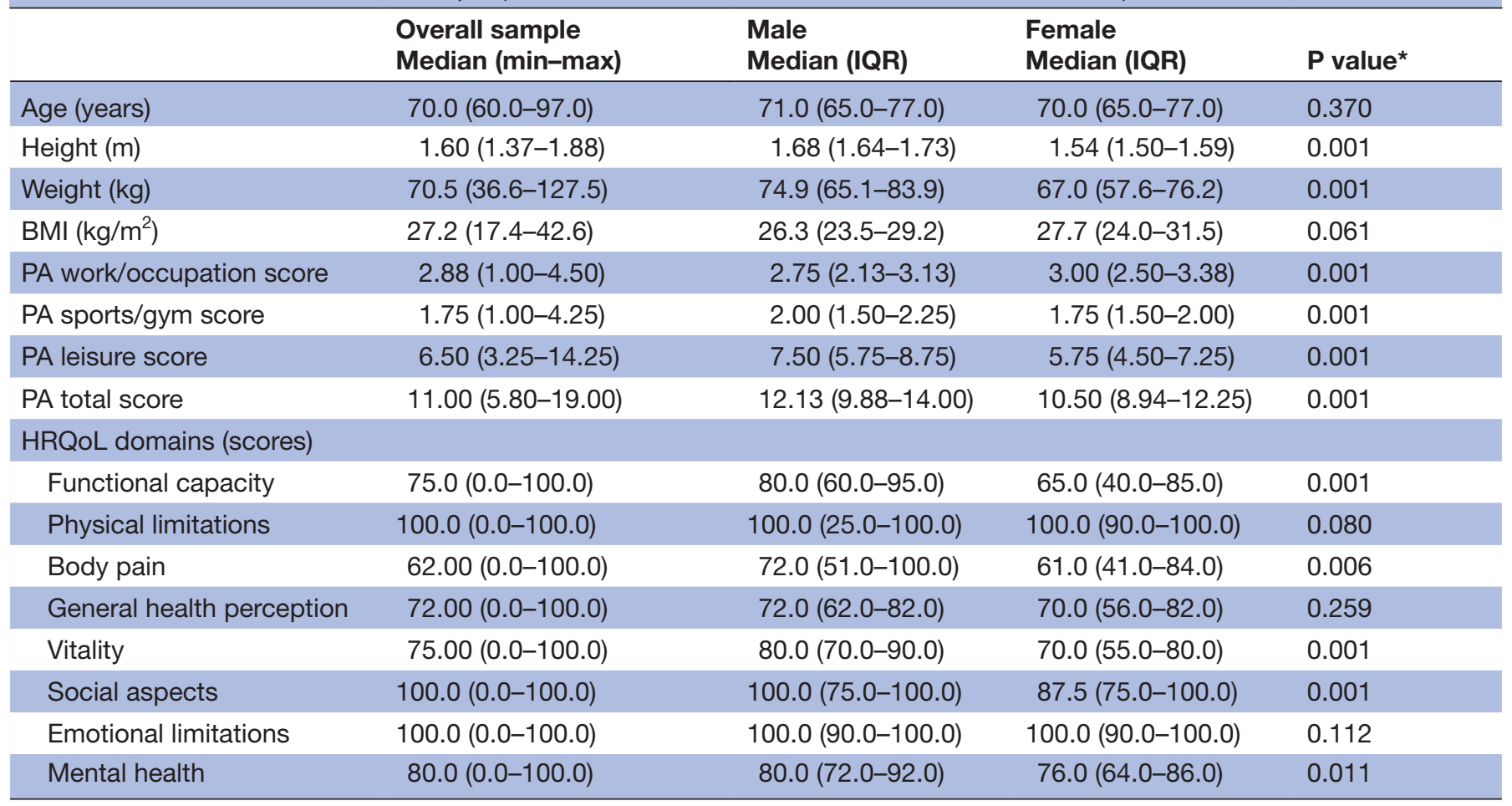

${ }^{*} P$ value for the Mann-Whitney $U$ test.

$\mathrm{BMI}$, body mass index; HRQoL, health-related quality of life; max, maximum value; min, minimum value; PA, physical activity.

Table 2 presents the associations related to PAs performed at work or in domestic occupations, sports practice and/or practices of activities performed at a gym, activities performed during leisure time and/or during transportation, and the total sum of these activities, with the eight domains of HRQoL. The practice of PA in work/occupation was associated with a higher HRQoL considering the domain of functional capacity. Older adults who participated in sports practices or activities in a gym presented a better general health perception. There was no significant association between being highly active in the leisure domain or during transportation and the domains of HRQoL. Regarding the total score of PA domains, highly active older adults presented a higher HRQoL in relation to functional capacity, perception of less body pain and social aspects than less active older adults.

Tables 3 and 4 present information on the magnitude of associations between the different domains of PA and the domains of HRQoL. In the work/occupation domain, the highly active older adults were $73 \%$ more likely to demonstrate better functional capacity and $61 \%$ more likely to have a better global health perception than the less active older adults. High PA through gym practice and/or sports practice was associated with more than $70 \%$ higher functional capacity, even after adjustment for comorbidities. In regard to the PA in leisure time, highly active older adults were $75 \%$ more likely to have better functional capacity, $74 \%$ more likely to have less body pain and $67 \%$ more likely to have better mental health than the less active participants, while body pain and mental health remained significant even after adjustment for comorbidities. When analysing the three domains of PA together in total score, highly active older adults were $77 \%$ more likely to have high HRQoL for functional capacity than the less active older adults. However, none of the observed associations remained significant at the 99\% CI level.

\section{DISCUSSION}

In the present study, the highly active older adults presented different associations with HRQoL domains, according to PA domains. Highly active older adults in the work/occupational PA domain presented higher scores in better functional capacity and general health perception. Being highly active in sports and in total PA was associated with better scores in functional capacity. Those older adults who were highly active in the leisure time domain were more likely to have better scores in functional capacity, body pain and mental health

The majority of studies present the beneficial effects of total PA on physical and mental health in general. ${ }^{30}$ However, when different contexts in which PA can be explored are analysed separately, just as the different perceptions of HRQoL are reported separately by domains, the results should be observed more carefully. For example, the older adults classified as highly active at work or in domestic occupations demonstrated better functional capacity. In contrast to these results, Jurakić 
Table 2 Prevalence of highly active older adults according to the HRQL domains

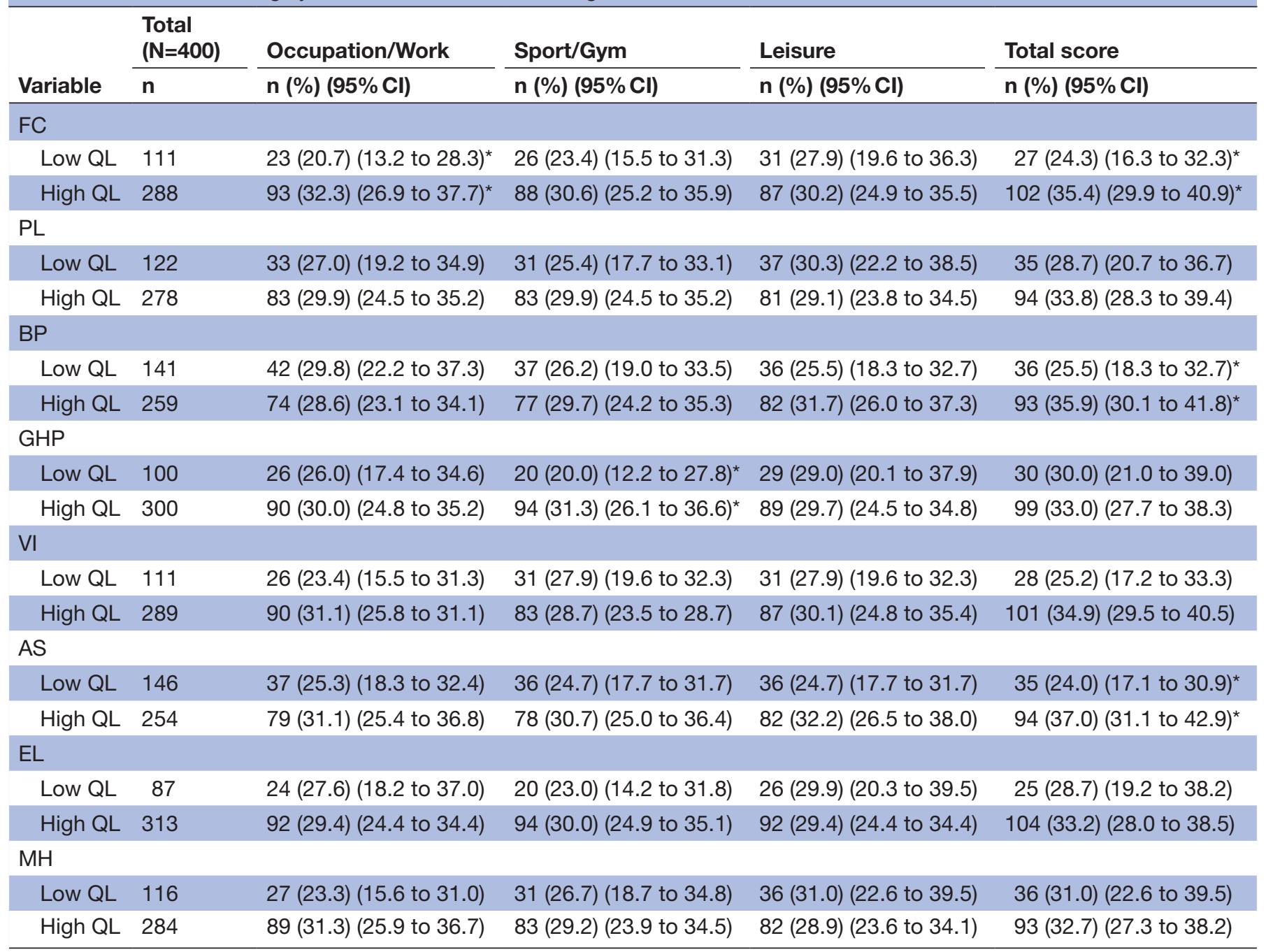

*Statistical difference by $\chi^{2}$ test for distribution.

BP, body pain; EL, emotional limitations; FC, functional capacity; GHP, general health perception; HRQoL, health-related quality of life; MH, mental health; PL, physical limitations; QL, quality of life; SA, social aspects; VI, vitality.

$e t a \ell^{11}$ found an inverse relationship between this domain and quality of life, showing that sufficiently active people in domestic activities reported having more pain in the body, probably due to repetitive movement efforts that may be part of the PA of that domain. However, older adults who are physically able to continue working, whether in the work environment or household work, are likely to preserve the ability to perform activities of daily living. On the other hand, those who opt for a lifestyle with insufficient practice of PA tend to accentuate the physiological processes of ageing.

In relation to PA related to sports practices or exercises performed at a gym, the results of the present study presented better HRQoL for the functional capacity domain, regardless of the presence of comorbidities. These results are in agreement with Takata $e t a l,{ }^{32}$ who verified that training directed to physical abilities can improve functional capacity and quality of life in general.
In the case of PA in the field of leisure and/or transportation, several studies have presented associations between this domain and quality of life..$^{33-35}$ The present study observed a significant association between being highly active in leisure time with better scores in functional capacity, body pain and mental health. In this way, PA in leisure time can provide benefits for physical health and for mental health, noting that neuropsychiatric diseases are increasingly affecting older people. ${ }^{36}$ In addition, the infrastructure of sidewalks and streets, as well as the insecurity of older adults, can demotivate this population from opting for active transportation, and consequently limit the increase in the benefits of this domain of PA on quality of life.

When total PA was analysed, using the sum of all domains, the results presented better HRQL for functional capacity. These results corroborate the findings in the literature suggesting that people who present 


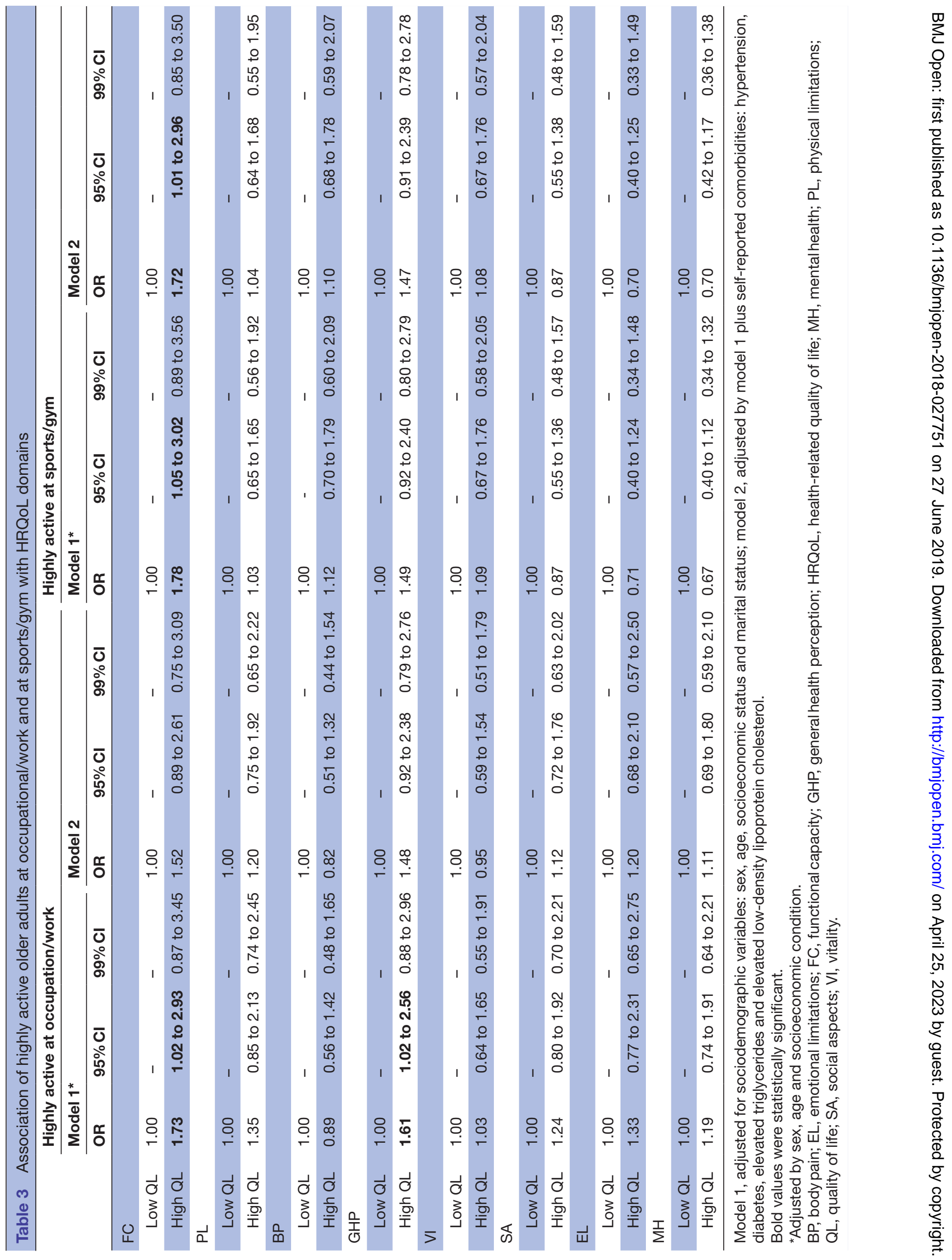




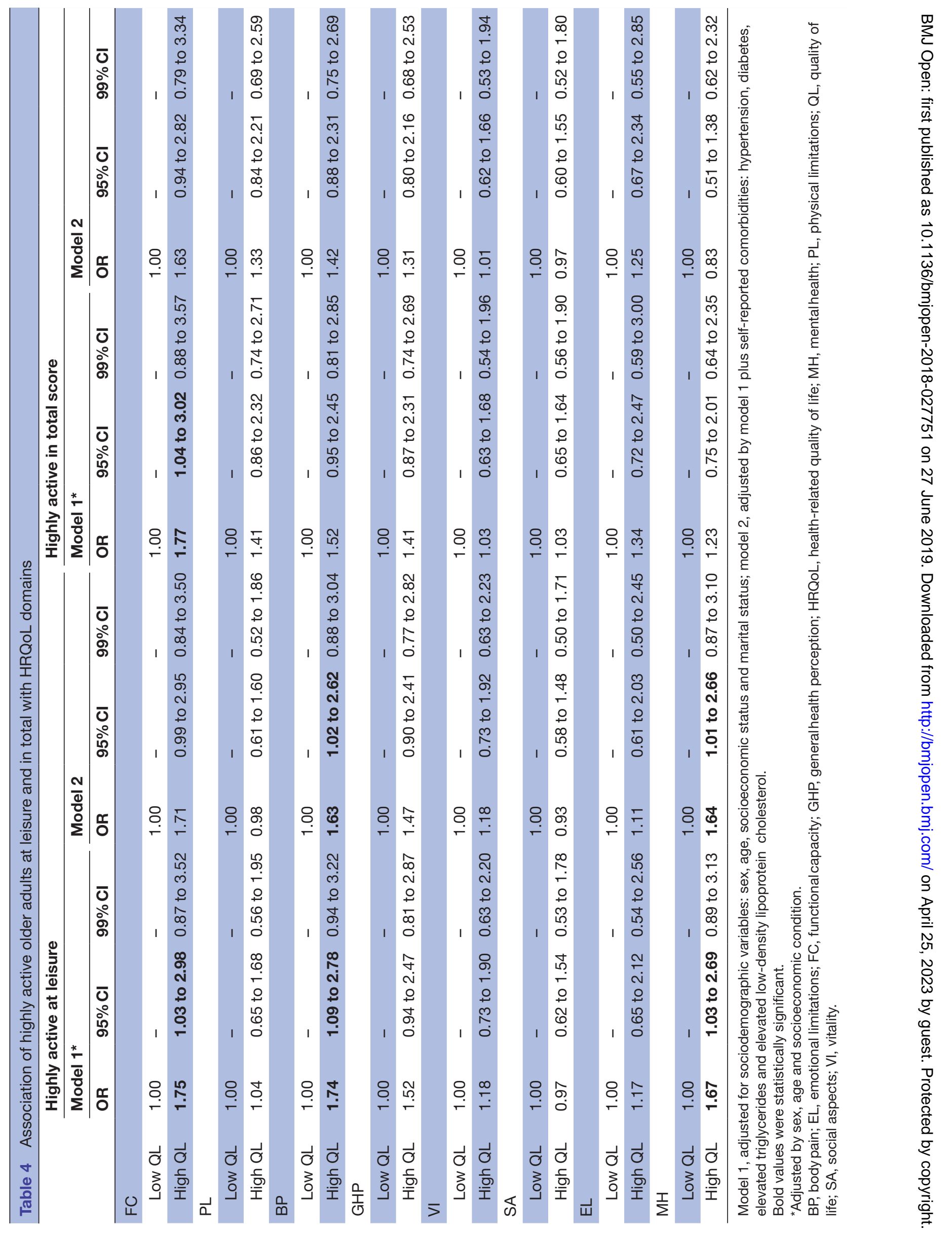


higher levels of PA may present better parameters of HRQoL. ${ }^{37-39}$ In this sense, the accumulation of PAs of different domains and intensities may be able to positively affect HRQoL, due to the increase in global levels of PA.

Despite evidence of the benefits that an active lifestyle provides for older adults, ${ }^{10}$ the use of different tools in other studies to analyse the HRQoL and each domain of PA separately, as well as total PA, makes it difficult to compare results. The majority of studies use either total PA or the leisure time domain as an outcome, making it difficult to compare our findings with other domains, such as activities in the work environment or in domestic occupations, and activities practised at a gym, and their relation with HRQoL. In addition, there is a lack of knowledge about this relationship in countries with low and medium socioeconomic conditions, as is the case of Brazil. $^{32} 40-42$

One of the novelties of the present study is the analysis of different domains of PA. The majority of studies that aimed to verify the relationship between the practice of $\mathrm{PA}$ and HRQoL in older adults considered only an isolated domain or PA as a whole (considering all domains of PA in a single block). Each PA domain has specific characteristics and must be considered in this relationship. Another factor is the adjustment of this relationship for comorbidities, since they are important health risk factors that may interfere in this relationship. In addition, PA assessment by domains can help to prevent the health costs generated by insufficient PA practice. ${ }^{43}$

The present study has some limitations. The cross-sectional design of this study does not allow cause-and-effect inference. The use of a questionnaire to assess the level of PA did not allow a more robust assessment, although the instrument used has been validated for older adults ${ }^{27}$ and is widely used in the scientific community, in addition to being validated against gold standard instruments for PA measurement such as doubly marked water. ${ }^{44}$ The Baecke Questionnaire does not provide information about duration and intensity of PA, which does not allow classification of the individuals into physically active according to the global recommendations. Due to this lack of classification, the sample was categorised into quartiles, and the fourth quartile was considered the most active, which necessarily divides the sample at $75 \%$ of its distribution, independently of how active they were compared with other populations or global recommendations. The present study was also limited through the assessment of comorbidities, where the types were restricted. For instance, osteoarthritis could have an impact on PA and HRQoL and was not included, and therefore this is considered one of the limitations of the study. Weekly energy consumption related to PA, sarcopaenia or frailty, and previous functionality (eg, Barthel Index score) were not measured, which is another limitation of the present study, as all of these are confounding variables in the relationship between PA and HRQoL. The levels of PA in each domain can be influenced by cultural differences, climatic factors and developmental factors of each region and/or country, suggesting that the results should be interpreted with caution, since the present study was developed in only one Brazilian city and cannot be generalised to other regions of Brazil or other countries. A final limitation is that there are no data available on how many potential participants declined to participate when invited since whenever the participant declined to participate in the study the next household was visited until the required sample size was reached. Furthermore, the observations did not remain significant at the 99\% CI level, and may therefore have been susceptible to a false-positive bias. A possible hypothesis is due to the limitation of sample size, which was calculated at a confidence level of $95 \%$ and compromised the power of evidence in the adjustment for multiple comparisons.

However, it is worth emphasising the importance of studies with older adults, who comprise the fastest growing age group in the world, and have consequently changed demographic and epidemiological patterns. In addition, this population has the largest prevalence of comorbidities, ${ }^{45}$ which seriously compromise quality of life in the physical domain and tend to also affect psychological health, ${ }^{46}{ }^{47}$ and the practice of PA may promote improvement in HRQoL regardless of these health problems, mainly in relation to the sports domain.

As positive aspects, we highlight the random sample and the control of the variables by confounding factors in the analyses between PA and HRQoL. We also emphasise the evaluation of PA addressing different domains in older adults and considering the different domains of HRQoL. In addition, it is worth noting the collection and storage of data through electronic devices, optimising the time in the collection process in the residences of the participants, as well as minimisation of errors during data export and tabulation, which are complex tasks in a population study.

The results of the present study suggest the different domains of PA in work/occupation, sports/gym and leisure/transportation activities are related in different and specific ways to the different domains of HRQoL. In addition, the practice of PA was related to higher HRQL in older adults in the different domains and in their entirety. Our findings reinforce the importance of studies encompassing different domains of PA for older adults, especially in middle-income countries. Taking advantage of public spaces to encourage and promote group activities for this population, especially in relation to the leisure time domain, could be a positive strategy.

\section{CONCLUSION}

Given the results and despite presenting limitations in relation to the confounding factors that may influence the variables analysed in the present study, it is suggested that older adults involved in some kind of sport or in gym activities, usually practised in groups, presented better functional capacity, regardless of the presence of comorbidities. Thus, exploring PA separately by domains may be 
an important tool for monitoring and promoting more active and healthy lifestyles, and consequently preserving HRQoL during ageing.

\section{Author affiliations}

${ }^{1}$ Physical Education, Universidade Estadual Paulista Julio de Mesquita Filho, Faculdade de Ciencias e Tecnologia, Campus de Presidente Prudente, Presidente Prudente, São Paulo, Brazil

${ }^{2}$ Physical Education Department, Universidade Estadual de Londrina (UEL), Londrina, Paraná, Brazil

${ }^{3}$ Universidade Estadual Paulista Julio de Mesquita Filho, Instituto de Biociencias, Campus de Rio Claro, Rio Claro, São Paulo, Brazil

Contributors All authors named in this paper-CCS, ESC, PMN, WRT, DdSC, LAG and DGDC - participated in the present study based on the following four criteria about authorship recommendations: substantial contributions to the conception or design of the work; or the acquisition, analysis or interpretation of data for the work; drafting the work or revising it critically for important intellectual content; final approval of the version to be published; and agreement to be accountable for all aspects of the work in ensuring that questions related to the accuracy or integrity of any part of the work are appropriately investigated and resolved.

Funding This work was supported by the São Paulo Research Foundation (FAPESP) (grant number 2019/10027-0).

Competing interests None declared.

Patient consent for publication Not required.

Ethics approval All procedures performed in studies involving human participants were in accordance with the ethical standards of the institutional and/or national research committee and with the 1964 Helsinki Declaration and its later amendments or comparable ethical standards. Informed consent was obtained from all individual participants included in this study. The Research Ethics Committee Involving Human Beings of UNESP - São Paulo State University approved this study (protocol: 45486415.4.0000.5402).

Provenance and peer review Not commissioned; externally peer reviewed.

Data sharing statement All data generated or analysed during this study are included in this published article.

Open access This is an open access article distributed in accordance with the Creative Commons Attribution Non Commercial (CC BY-NC 4.0) license, which permits others to distribute, remix, adapt, build upon this work non-commercially, and license their derivative works on different terms, provided the original work is properly cited, appropriate credit is given, any changes made indicated, and the use is non-commercial. See: http://creativecommons.org/licenses/by-nc/4.0/.

\section{REFERENCES}

1. WHO. on Noncommunicable Diseases. Glob Status Rep Noncommunicable Dis 2014:1-302.

2. Kohl HW, Craig CL, Lambert EV, et al. The pandemic of physical inactivity: global action for public health. The Lancet 2012;380:294-305.

3. WHO | The top 10 causes of death. WHO. Published Online First: 2017. http://www.who.int/mediacentre/factsheets/fs310/en/index1. html\#.W93yil8e0ic.mendeley.

4. Reis RS, Salvo D, Ogilvie D, et al. Scaling up physical activity interventions worldwide: stepping up to larger and smarter approaches to get people moving. The Lancet 2016;388:1337-48.

5. Del Duca GF, Nahas MV, de Sousa TF, et al. Clustering of physical inactivity in leisure, work, commuting and household domains among Brazilian adults. Public Health 2013;127:530-7.

6. Dao-Tran T-H, Seib C, Jones L, et al. A cross-cultural comparison of health-related quality of life and its associated factors among older women in Vietnam and Australia. BMC Res Notes 2018;11:174.

7. Flor LS, Campos MR, Laguardia J. Quality of life, social position and occupational groups in Brazil: evidence from a population-based survey. Rev Bras Epidemiol 2013;16:748-62.

8. Rodrigues GH de P, Gebara OCE, Gerbi CC da S, et al. Depression as a clinical determinant of dependence and low quality of life in elderly patients with cardiovascular disease. Arq Bras Cardiol 2015;104:443-9.
9. Heesch KC, van Gellecum YR, Burton NW, et al. Physical activity and quality of life in older women with a history of depressive symptoms. Prev Med 2016;91:299-305.

10. Guedes DP, Hatmann AC, Martini FAN, et al. Quality of life and physical activity in a sample of brazilian older adults. J Aging Health 2012;24:212-26.

11. Vagetti GC, Filho VCB, Moreira NB, et al. The association between physical activity and quality of life domains among older women. $J$ Aging Phys Act 2015;23:524-33.

12. Dale CE, Bowling A, Adamson J, et al. Predictors of patterns of change in health-related quality of life in older women over 7 years: evidence from a prospective cohort study. Age Ageing 2013;42:312-8

13. Vagetti GC, Barbosa Filho VC, Moreira NB, et al. Association between physical activity and quality of life in the elderly: a systematic review, 2000-2012. Revista Brasileira de Psiquiatria 2014;36:76-88.

14. Tampubolon G. Delineating the third age: joint models of older people's quality of life and attrition in Britain 2002-2010. Aging Ment Health 2015;19:576-83.

15. Wafa SW, Shahril MR, Ahmad AB, et al. Association between physical activity and health-related quality of life in children: a crosssectional study. Health Qual Life Outcomes 2016;14:71.

16. Yasamy MT, Dua T, Harper M, et al. a Growing Concern. Ment Heal Older Adults 2012:4-9.

17. Instituto Brasileiro de Geografia e Estatística - IBGE. Projeção da população do brasil por sexo e idade para o período 2000/2060 projeção da população das unidades da federação por sexo e idade para o período 2000/2030 Agosto de. 2013:21.

18. Bauman AE, Reis RS, Sallis JF, et al. Correlates of physical activity: why are some people physically active and others not? The Lancet 2012;380:258-71.

19. Marshall SC, Berg K. Cessation of exercise in the institutionalized elderly: effects on physical function. Physiotherapy Canada 2010;62:254-60.

20. Balboa-Castillo T, León-Muñoz LM, Graciani A, et al. Longitudinal association of physical activity and sedentary behavior during leisure time with health-related quality of life in community-dwelling older adults. Health Qual Life Outcomes 2011;9:47.

21. Marques LP, Schneider IJC, d'Orsi E. Quality of life and its association with work, the Internet, participation in groups and physical activity among the elderly from the EpiFloripa survey, Florianópolis, Santa Catarina State, Brazil. Cadernos de Saúde Pública 2016;32:e00143615.

22. Elhakeem A, Hardy R, Bann D, et al. Intergenerational social mobility and leisure-time physical activity in adulthood: a systematic review. $J$ Epidemiol Community Health 2017;71:673-80.

23. Brazilian Institute of Geography and Statistics. $2010 \mathrm{https} / / /$ cidades. ibge.gov.br/brasil/sp/presidente-prudente/panorama (Accessed 3 Nov 2018).

24. Hajian-Tilaki K. Sample size estimation in epidemiologic studies. Caspian J Intern Med 2011;2:289-98.

25. Freitas Junior IF, Bueno DR, Buonani C, et al. Padronização de técnicas antropométricas. São Paulo Cult Acadêmica 2009.

26. Baecke JA, Burema J, Frijters JER. A short questionnaire for the measurement of habitual physical activity in epidemiological studies. Am J Clin Nutr 1982;36:936-42.

27. Florindo AA, Latorre M, Jaime PC, et al. Methodology to evaluation the habitual physical activity in men aged 50 years or more]. Rev Saude Publica 2004;38:307-14.

28. Ware JE, Snow KK, Kosinski M, et al. SF-36® Health Survey Manual andlnterpretation Guide. Boston, MA: New England Medical Center, The HealthInstitute, 1993 WareetalSF-36UserManual_27MB 1993 316 pp.pdf.

29. Kamakura W, Mazzon A. Alterações na aplicação do Critério Brasil, válidas a partir de 16/04/2018. 2018;2015:1-6.

30. Xu F, Cohen SA, Lofgren IE, et al. Relationship between diet quality, physical activity and health-related quality of life in older adults: Findings from 2007-2014 national health and nutrition examination survey. J Nutr Health Aging 2018;22:1072-9.

31. Jurakić D, Pedišić Željko, Greblo Z. Physical activity in different domains and health-related quality of life: a population-based study. Quality of Life Research 2010;19:1303-9.

32. Takata Y, Ansai T, Soh I, et al. Quality of life and physical fitness in an 85-year-old population. Arch Gerontol Geriatr 2010;50:272-6.

33. Pucci G, Reis RS, Rech CR, et al. Quality of life and physical activity among adults: population-based study in Brazilian adults. Quality of Life Research 2012;21:1537-43.

34. Vallance J, Eurich D, Gardiner P, et al. ASsociations of daily pedometer steps and self-reported physical activity with healthrelated quality of life: Results from the alberta older adult health survey. J Aging Health 2016;28:661-74. 
35. Nakamura P, Teixeira I, Smirmaul BP, et al. Health related quality of life is differently associated with leisure-time physical activity intensities according to gender: a cross-sectional approach. Health Qual Life Outcomes 2014;12:98.

36. Teixeira JB, Roberto P, Higa J, et al. Mortality from Alzheimer's disease in Brazil, 2000-2009. Artigo 2015;31:1-12.

37. Heesch KC, van Gellecum YR, Burton NW, et al. Physical activity, walking, and quality of life in women with depressive symptoms. Am J Prev Med 2015;48:281-91.

38. Halaweh H, Willen C, Grimby-Ekman A, et al. Physical activity and health-related quality of life among community dwelling elderly. $J$ Clin Med Res 2015;7:845-52.

39. Koolhaas CM, Dhana K, van Rooij FJA, et al. Physical activity types and health-related quality of life among middle-aged and elderly adults: The Rotterdam Study. J Nutr Health Aging 2018;22:246-53.

40. Beenackers MA, Kamphuis CBM, Giskes K, et al. Socioeconomic inequalities in occupational, leisure-time, and transport related physical activity among European adults: A systematic review. Int J Behav Nutr Phys Act 2012;9:116.
41. Mielke GI, da Silva ICM, Owen N, et al. Brazilian adults' sedentary behaviors by life domain: population-based study. PLoS One 2014;9:e91614.

42. Müller AM, Ansari P, Ebrahim NA, et al. Physical activity and aging research: A bibliometric analysis. J Aging Phys Act 2016;24:476-83.

43. Codogno JS, Turi BC, Kemper HCG, et al. Physical inactivity of adults and 1-year health care expenditures in Brazil. Int J Public Health 2015;60:309-16.

44. Philippaerts R, Westerterp K, Lefevre J. Doubly labeled water validation of three physical activity questionnaires. Int J Sports Med 1999;20:284-9.

45. Divo MJ, Martinez CH, Mannino DM. Ageing and the epidemiology of multimorbidity. Eur Respir J 2014;44:1055-68.

46. Gu J, Chao J, Chen W, et al. Multimorbidity and health-related quality of life among the community-dwelling elderly: A longitudinal study. Arch Gerontol Geriatr 2018;74:133-40.

47. de NTCM, Jaluul O, Machado AN, et al. Quality of life and multimorbidity of elderly outpatients. Clinics 2009;64:45-50. 